\title{
Culturally Adapted Psychoeducation among Family Caregivers of Schizophrenic Clients: A Scoping Review
}

\author{
Imas Rafiyah ${ }^{1,2 *}$ (D) Suryani Suryani ${ }^{1}$ D , Laili Rahayuwati ${ }^{3}$, Wandee Suttharangsee $^{4}$ (D) \\ ${ }^{1}$ Department of Mental Health Nursing, Faculty of Nursing, Universitas Padjadjaran, Bandung, Indonesia; ${ }^{2}$ Doctoral Program \\ Candidate of Medical Sciences, Faculty of Medicine, Universitas Padjadjaran, Bandung, Indonesia; ${ }^{3}$ Department of Fundamental \\ of Nursing, Faculty of Nursing, Universitas Padjadjaran, Bandung, Indonesia; ${ }^{4}$ Education and Innovative Learning Academy, \\ Prince of Songkla University, Songkhla, Hatyay, Thailand
}

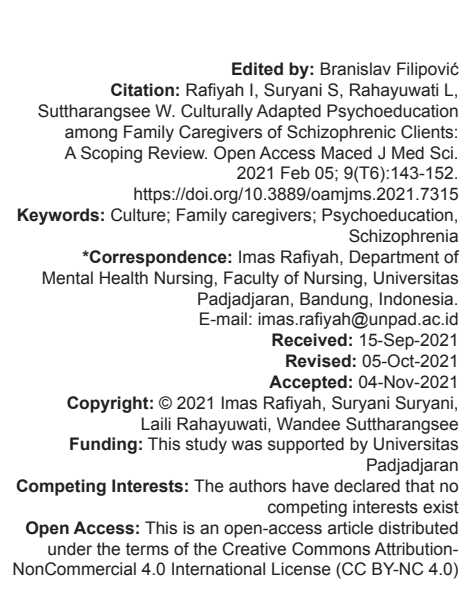

\section{Introduction}

Schizophrenia is one of the severe and chronic mental illnesses. According to DSM V, schizophrenia is two or more symptoms such as delusion, hallucination, disorganization speech, catatonic behavior, affective flattening, avolition, and alogia that arise during 1 month. Then, it continuous persists for at least 6 months [1]. In the same year, the prevalence of schizophrenia in various countries ranged from $0.21 \%$ to $0.24 \%$ [2]. Even though the number of this prevalence is not quite high, the disease has become a concern of the entire mental health organization because of its negative effects.

People with schizophrenic might have functional dysfunction caused by brain disorder. Review from 104 papers study showed that people with schizophrenia experienced disability in psychosocial function, mental function, and activity limitation or restriction. From all of functions, psychosocial function is more experienced than others. Moreover, the disease can relapse that impact on high cost because of rehospitalization [3].
Therefore, the disease is included in one of the global burden diseases [4].

Taking into account various things, mental health policy has shifted from hospital-based care to community-based care since 1960. The World Health Organization has recommended this policy for various countries in the world in 2001 [5]. It means that caring for client with schizophrenia is more focused on the community than hospital as it would increase mental health in a community and decrease relapse [6]. However, the lack of mental health services in the community [7], especially in developing countries, has resulted in the role of the family being crucial as an extension of nurses in caring for clients with schizophrenia.

A family is two or more individuals who are joined because of certain ties such as blood relation or marriage [8]. In a family, there is a family member who cares voluntarily other family members who are sick that is known as a family caregiver [9]. Family caregiver can help client with schizophrenia in terms of fulfill daily activities and treatments [10] in various level of assistance either partially or fully. 
Caring for clients with schizophrenia has both positive and negative effects for family caregivers themselves. On the one hand, caring for client with schizophrenia can cause increase relationship, responsibility, efficacy, spirituality, and selfgrowth [11]. On the other hand, it can causes physical problems such as fatigue, lack of sleep, headache; psychological problems for instance depression and others; and socioeconomic problems [12]. However, studies had showed that family caregivers of client with schizophrenia more experienced psychosocial problems [13], [14]. Indeed, these effects depend on family caregivers' coping [15], [16], severity of clients' symptom [13], [17], or stigma [18].

Unresolved psychosocial problems faced by family caregivers' have impacted on high emotional expression, such as frequent criticism or over involvement [19]. All of these causes low quality of care provided by family caregivers to schizophrenic clients [20]. Furthermore, it results on relapse and rehospitalization [21], [22] that consequence on high cost incurred by both the family and the government [23].

Role of family caregivers is crucial while caring schizophrenic client, so they must be involved in mental health services. Professional mental health services need to provide appropriate intervention for family caregiver. Studies have proved some interventions to overcome problems of family caregivers caring for schizophrenia [24]. From some these interventions, psychoeducation is one of the interventions supported by many evidence [25].

Psychoeducation is a structured and systematic program provided by mental health professional which includes providing information about illness and how to adapt with the problems during caring [26]. Through psychoeducation, family caregivers of schizophrenic clients will be offered information related to the disease and its treatments. Moreover, they will be offered skill training to adapt with stressor situation during caring. Through this program, family caregivers are expected capable to care client with schizophrenia.

Psychoeducation was originally developed from Western countries [27], [26], [28]. Although this intervention has robust evidences, applications of it on different culture background are still necessary further investigation. For instance, one of the studies has conducted to evaluate effectiveness of the multifamily psychoeducation group on 34 Australian and 25 Vietnamese. Result showed that this intervention decreases burden of Australian but it did not decrease burden Vietnamese significantly. The difference cultural background might be correlated with this result [29] since culture is set of values, belief, attitudes, and behaviors shared by a group of people and communicated from one generation to the next [30]. Furthermore, it influences how individual thinks and behaves [31]. Thus, psychoeducation should be modified systematically according to certain group culture including language, belief, and norm. It is well known as a culturally adapted psychoeducation [32].

Some studies have conducted culturally adapted psychoeducation for family caregivers of client with schizophrenia but it was still doubt. For example, one study investigated relevant psychoeducation for Korean family caregiver and this intervention improves their coping and empowerment [33]. Another study attempted to develop a cultural appropriate psychoeducation program for Chinese population but the result had not addressed most of the important cultural issues related to mental illness [34]. Therefore, the question is how they developed culturally adapted psychoeducation for family caregivers of client with schizophrenia.

How previous studies developing culturally adapted psychoeducation for family caregivers of client with schizophrenia are crucial to be investigated since it will offer an understanding of which way is appropriate for future studies. However, the previous studies related to its intervention have not been documented clearly. Hence, the purpose of this review is to map previous studies of culturally adapted psychoeducation for family caregivers of schizophrenia clients including type of study, intervention of culturally adapted psychoeducation, and outcomes.

\section{Methods}

The scoping review method used in this review follows the Arksey and O'Malley approach [35]. This method consists of five stages, namely, identifying the research question, identifying relevant studies, study selection, charting the data, and collating, summarizing, and reporting the result. The problem question in this scoping review is how research on culturally adapted psychoeducation for family caregivers of schizophrenic clients has been carried out. Sub-questions arise in planning this scoping review (Table 1).

Table 1: List of research questions and operational definitions

\begin{tabular}{ll}
\hline Research questions & Operational definitions \\
\hline What types of research that has been used & Primary research: Quasi-experiment \\
in the previous research? & RCT \\
How cultural-based psychoeducation has & Cultural-based psychoeducation \\
been carried out in the previous research? & intervention: \\
& Setting (hospital/community) \\
& Theories/model approach \\
& Content \\
& Session and duration \\
& Provider (health professional) \\
& Receiver (ethnics) \\
What are outcomes that have been carried & Health outcomes \\
out in the previous research? & Positive \\
& Negative \\
\hline
\end{tabular}

\section{Searching strategy for relevant study}

Before searching for relevant articles, eligibility criteria and databases were determined. Eligible 
articles reviewed were assigned by inclusion criteria and exclusion criteria. Inclusion criteria were set by population, content, and context (PCC approach) consisted of family caregiver population, culture and psychoeducation concept, and schizophrenic context. Non-primary research, nonexperiment studies, nonEnglish language, and restricted articles were excluded. Furthermore, the databases in this scoping review were assigned. These were CINAHL, PubMed, and Psyclnfo. The last process was searching strategy that was done through three stages:

\section{Stage one}

In this stage, the terms used developed from the research questions and key concept definitions for searching articles were set [35]. This review used major terms based on population, content, and context (PCC approach) including family caregiver population, culture and psychoeducation concept, and schizophrenic context. From the major terms, other terms were searched through MeSH and the synonym thesaurus. Furthermore, the Boolean term "OR" and Boolean term "AND" were used (Table 2).

Table 2: PCC grid for searching strategy

\begin{tabular}{|c|c|c|c|}
\hline PCC & Major term & Alternate term & Syntax \\
\hline Population & Family caregiver & $\begin{array}{l}\text { Family caregiver } \\
\text { Spouse caregiver* } \\
\text { Carer* } \\
\text { informal caregiver } \\
\text { unpaid caregiver } \\
\text { non-formal caregiver* } \\
\text { lay caregiver* }\end{array}$ & $\begin{array}{l}\text { Family caregiver* OR Spouse } \\
\text { caregiver* OR Carer* OR } \\
\text { informal caregiver* OR unpaid } \\
\text { caregiver* OR non-formal } \\
\text { caregiver* OR lay caregiver }{ }^{*} \text { OR } \\
\text { parent caregiver }\end{array}$ \\
\hline Content & Culture & $\begin{array}{l}\text { Culture* } \\
\text { belief* }^{\star} \\
\text { customs } \\
\text { cultural background } \\
\text { traditional indigenous } \\
\text { native } \\
\text { race } \\
\text { ethnic* } \\
\text { ethnicity } \\
\text { tribe }\end{array}$ & $\begin{array}{l}\text { AND } \\
\text { Culture* OR belief* } \\
\text { OR customs OR cultural } \\
\text { background OR cultural } \\
\text { relativism OR traditional OR } \\
\text { indigenous OR native } \\
\text { OR race OR ethnic* OR ethnicity } \\
\text { OR tribe* }\end{array}$ \\
\hline & Psychoeducation & $\begin{array}{l}\text { Psychoeducational, } \\
\text { psycho-education, } \\
\text { psycho-educational }\end{array}$ & $\begin{array}{l}\text { AND } \\
\text { Psychoeducation OR } \\
\text { psychoeducational OR } \\
\text { psycho-education OR } \\
\text { psycho-educational } \\
\text { AND }\end{array}$ \\
\hline Context & Schizophrenia & $\begin{array}{l}\text { Schizophrenia* } \\
\text { Schizophrenic } \\
\text { disorder* }^{*} \\
\text { Severe mental illness } \\
\text { psychosis }\end{array}$ & $\begin{array}{l}\text { Schizophrenia* } \\
\text { OR Schizophrenic disorder* } \\
\text { OR severe mental illness OR } \\
\text { psychosis OR mental disorder } \\
\text { OR delusion OR hallucination }\end{array}$ \\
\hline
\end{tabular}

Based on the syntax obtained, searching articles were carried out from each database with restrictions on abstract available and English language. After collecting the articles, these were exported to the endnote reference manager. These articles were screened by removing duplicate articles and sorted by reading abstract. Then, irrelevant articles were discarded by identifying title, population, and abstracts.

\section{Stage two}

In this stage, abstracts were read and keywords were identified from $10 \%$ of the relevant abstracts carried out. When new terms were not found, articles searching were stopped. However, the keywords or index terms were revised when different terms were found. After that, searching was continued comprehensively using keywords or index terms that had been revised.

\section{Stage three}

In this stage, appropriate articles and keywords traced through bibliography of abstracts and full papers. Then, those relevant articles were searched by Google Scholar search engine. If articles cannot be found by this way, authors were contacted.

\section{Study selection}

The articles selection was done through certain strategies and well-organized process. In this review, studies selection was done based on pre-determined inclusion and exclusion criteria. The screening process follows the flow of the ScR PRISMA diagram (Figure 1), including searching for articles through databases and additional sources, after that checking for duplicate articles and discarding duplicate articles. From the remaining articles, the relevant articles were checked through the title and abstract, then, the irrelevant articles were discarded. Furthermore, the full text of the relevant articles was read and the eligible articles were carried out. Those articles that meet the criteria were included in the review.

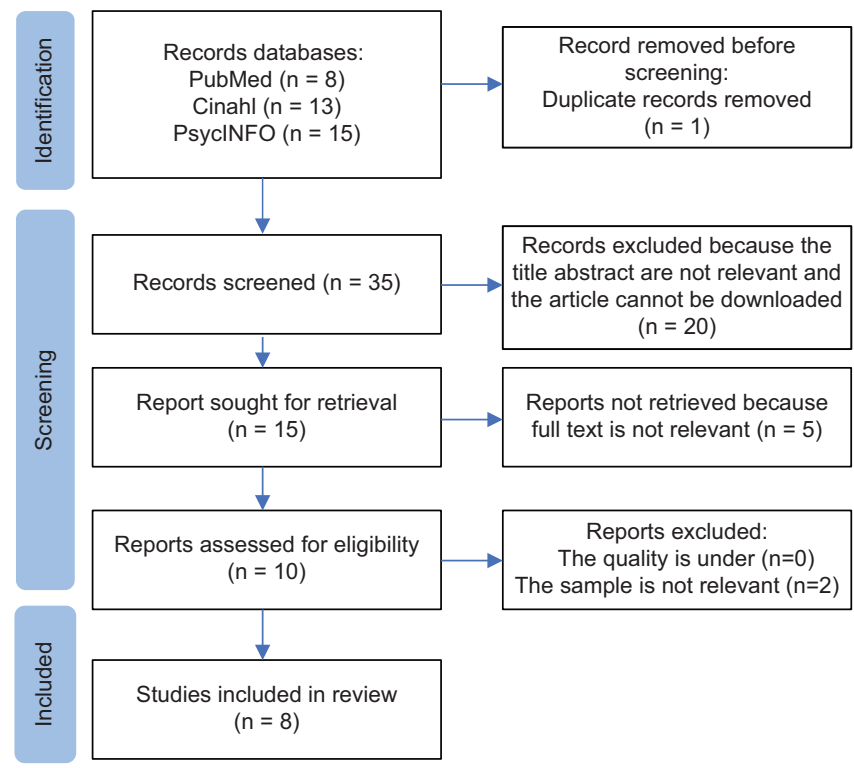

Figure 1: Data processing flowchart

\section{Quality appraisal process}

The selection involved two people on the team independently. When there was a discrepancy in determining of the articles, an agreement was made by two people in the team. If there was still no agreement, a third person outside the team is involved. 


\section{Data extraction and analysis}

The next stage is to map key items based on information obtained from eligible articles. In the extraction stage, the data sources that are appropriate with the objectives and research problems are summarized logically by tables with the Excel database program. First, a draft table is made, then tested and revised as needed during the data extraction process. The table includes authors, year of publication, country, purposes, samples, method, intervention, and outcome.

\section{Results}

\section{Literature search/study}

At the beginning of articles searching, 36 articles are found in the databases. Then, duplication articles were checked. There was one duplicate article, so the remaining articles were 35 . Of these, articles were screened by title and abstract and 20 articles were excluded from the study. Furthermore, 15 articles were retrieved for full-text review and five articles that were not relevant were excluded from the study. Then, 10 articles were remaining and two were excluded. Last, articles remaining that met inclusion criteria were eight articles.

\section{Study characteristics}

A total of eight studies were included in this review. Of these, five articles were RCT, one was quasiexperiment without control group, and two articles were quasi-experiment with control group. Studies were conducted in the USA (four studies), Canada (one study), Japan (one study), Egypt (one study), and Pakistan (one study). Races included in studies were Chinese-American, Japanese, Egyptian, Pakistan, Korean, Chinese, Tamil, Mexican-American, and Latino. Setting was outpatient (six studies), inpatient (one study), and in the community (one study).

\section{Culturally adapted psychoeducation implementation}

Psychoeducation provided for family caregiver of client with schizophrenia was varied. Health professional offered the intervention were psychiatrist, social worker, psychologist, nurse, and occupational therapist. Psychoeducation approach mostly used multifamily group psychoeducation model developed by McFarland, and others such as Anderson and Fallon. Culture adapted approach used explanatory models, cultural exchange theory, and the tenets of strengthoriented approaches. Most of psychoeducation was delivered through face to face either for single or group.
Receiver included family caregiver and schizophrenic client or family caregiver only or patient only. Media used were lecture, discussion, video, leaflet, and workshop. The longest duration of intervention was 12 months (two studies) while the shortest was 2 months (one study). The most frequent session was 24 , but the least was 10 session. Duration each session was 1-2 h. Psychoeducation was included education about schizophrenia and skill to overcome problem. Content of culturally adapted was changing attitude including belief and norm. One study focuses on the keys adaptation including language, concepts, family, communication, content, cultural specific norm, and context. Only three studies did follow up: Two studies 3 months follow-up, and one study $4,8,12,18$, and 24 months.

\section{Output of studies}

Positive outcomes were quality of life, social adjustment, social functioning, coping skill, family empowerment, knowledge, family well-being, family warmth, social support, treatment satisfaction, and service use. Negative outcomes were burden, anxiety, perceived criticism, stigma, depression, family rejection, expression emotion, medication adherence, medication compliance, frequent hospitalization, and severity symptoms. Outputs of the previous studies were objected both for family caregiver and patients with schizophrenia. Most of output for family caregiver was burden followed by coping and stigma. In terms of patient, output about symptoms was the highest followed by social function and quality of life.

\section{Discussion}

The purpose of this review was to identify the previous study about culturally adapted psychoeducation for family caregivers with schizophrenic clients. Psychoeducation has been proved as a robust intervention for family caregiver caring for schizophrenia. However, application of this intervention for family caregiver of schizophrenic client with different culture background needs to be investigated further to increase their acceptance. How the previous studies developed culturally adapted psychoeducation for family caregiver of schizophrenic client have not been known clearly.

Eight articles presenting culturally adapted psychoeducation for family caregivers on schizophrenic clients have been found. According to the reviews of those articles, most of studies were done in Asian such as Chinese, Japan, Korean, Tamil, Indian, Egyptian, and Pakistan. This is probably Asia is the largest continent in the world. However, culturally adapted 


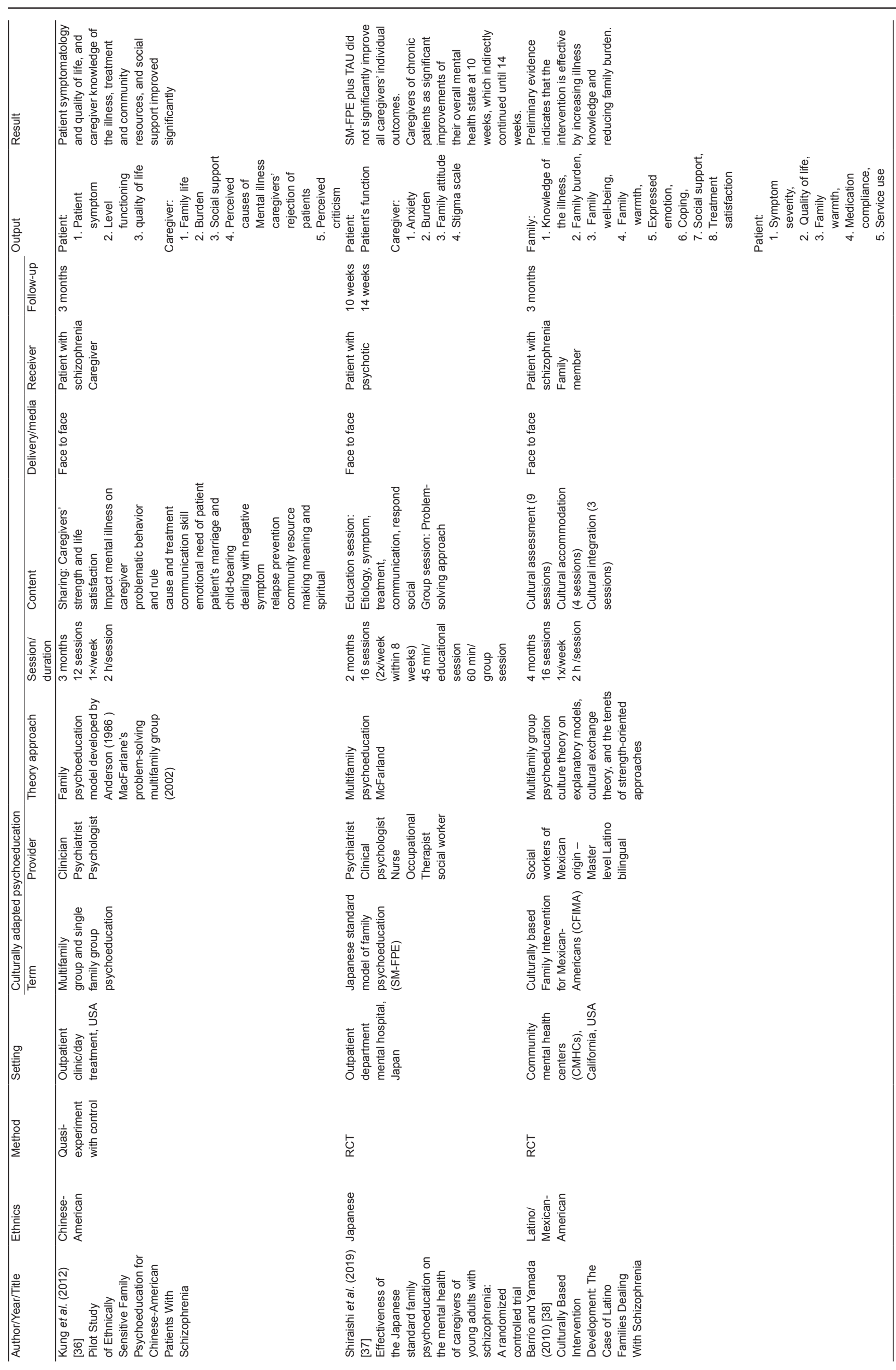




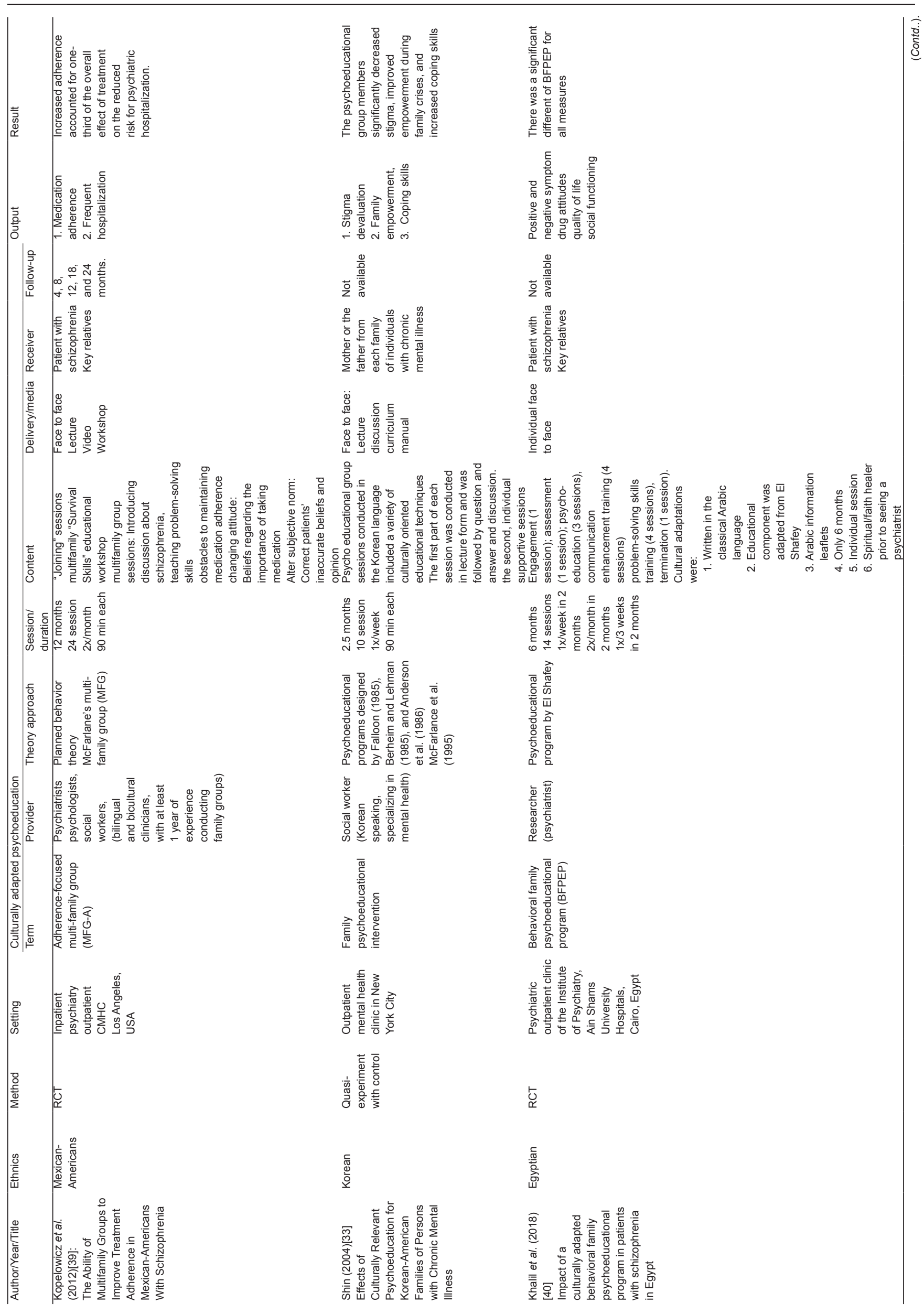




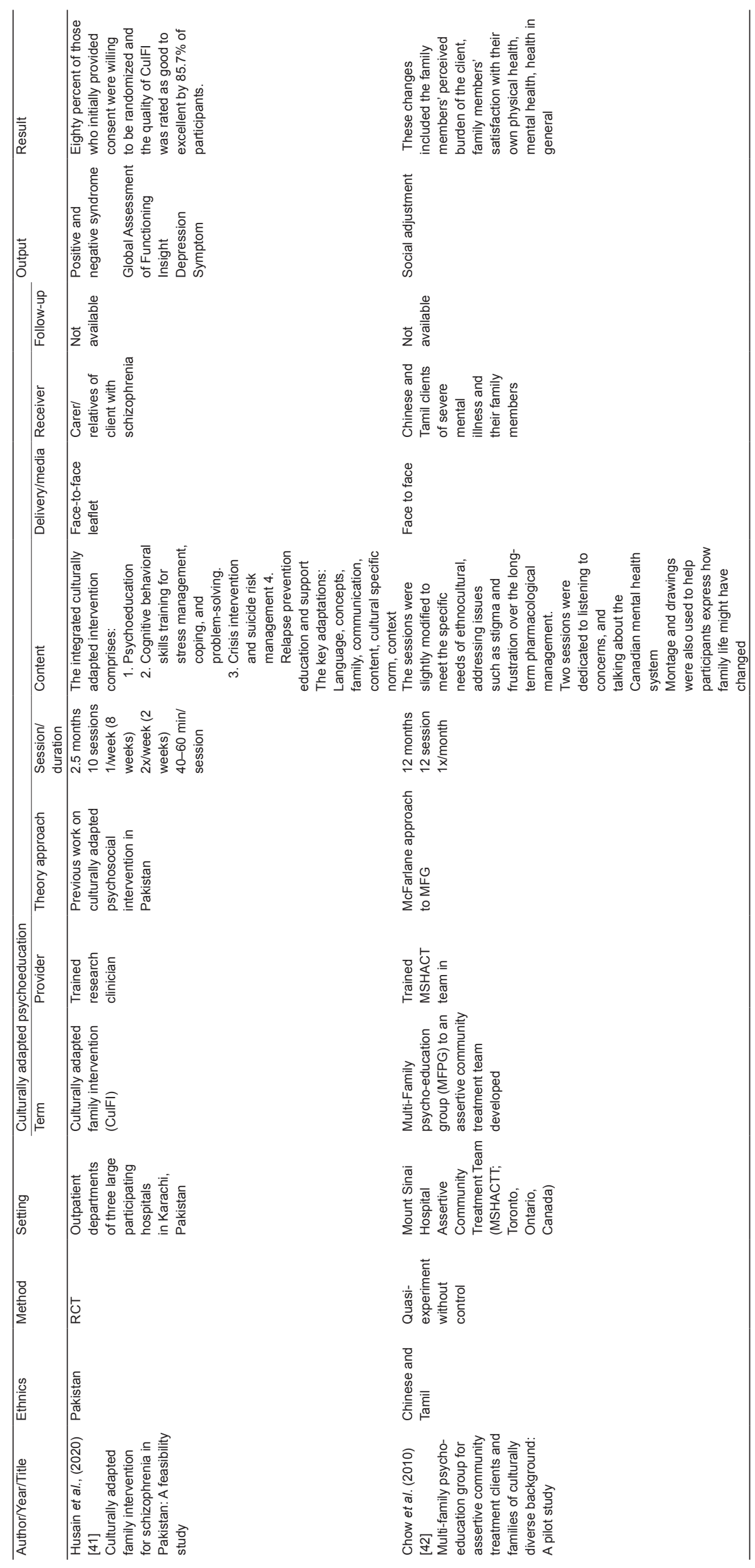


psychoeducation needs to be developed and proven in other ethnic as each ethnic has its own uniqueness, especially related to mental health.

Theory and model underlying culturally adapted psychoeducation were psychoeducation and culture. In the previous studies, multifamily group psychoeducation developed by McFarlane was the most theory used than others. Multifamily psychoeducation is a therapeutic process aimed for families or family caregivers to help them increasing knowledge and skills to deal with distress while caring for ill family members. This intervention was done in group session. Through group session, family caregivers are expected to share experiences with others [26]. Being intervention which culture sensitive, the intervention needs incorporate with culture theory. Culture adapted approach in this articles review used explanatory models, cultural exchange theory, and the tenets of strength-oriented approaches.

Content psychoeducation was knowledge about schizophrenia and skill to cope with problems while caring. The keys culture adaptation including language, concepts, family, communication, content, cultural specific norm, and context. It was aimed to change attitude including belief and norm. Cultural adaptation refers to the systematic modification from protocol intervention including culture, language, and context that will be appropriate with client's culture [32]. Intervention that appropriates with family caregivers' culture will be more convenient for improve their behavior to be better in caring client with schizophrenia because culture influences how individual thinks and behaves and each group of people has different cultural background.

The previous studies on culturally adapted psychoeducation for family caregivers of schizophrenic clients have different sessions and durations. The longest duration of intervention was 12 months [39], [42] while the shortest was 2 months [37]. The most frequent session was 24 [39], but the least was 10 sessions [33]. Duration of each session was 1-2 $\mathrm{h}$. The longer the intervention is given, the deeper understanding of the family caregivers.

Most of psychoeducation was delivered through face to face such as lecture, discussion, workshop through media video, or leaflet. Materials delivered directly by these ways can be effective. Of this, immediate respond between sender and receiver will be obtained. Sender can evaluate directly feedback of receiver, so she/he can improve the intervention quickly. However, obstacles of this way are time, energy, and funding.

The professional health providing culturally adapted psychoeducation was mostly multidiscipline including psychiatrist, nurse, social worker, psychologist, and occupational therapy. Those were the professionals who had experience in mental health, who had been trained in psychoeducation, and who spoke in bilingual language. Psychiatrist was the most health professional offering the intervention among them as psychiatrist was one of the mental health professionals who have knowledge about schizophrenia and its treatment.

People who receive psychoeducation in these literature consisted of family caregiver and schizophrenic client or family caregiver only or patient only. Involvement schizophrenic client in the family psychoeducation intervention is more effective. The intervention will be successful if both family caregiver and their family member ill involve actively within the intervention. However, sometimes family caregivers might feel hesitate when they express their emotion feeling while caring. One study, which was conducted study in Japan, separated families and schizophrenic clients in the family group session of psychoeducation to avoid client's guilt to family [43].

The setting of the previous studies about culturally adapted psychoeducation for family caregivers on schizophrenic clients mostly was done in the outpatient department of hospital. It is a part of hospital that provides treatment and care for patients without stay overnight. Outpatient department was a place which was frequently visited by client and their relatives. Many clients with schizophrenia and their relatives come to this place for routine follow-up treatment. Thus, respondents who eligible with criteria were easier to be found.

Most of output for family caregiver was burden followed by coping and stigma. It is one important output because coping is effort to overcome excess stressor. Stigma also is a one of the important thing to evaluate because stigma might make depression feeling. Limitation of this review was lack of the databases. Therefore, possibility of the related articles has not been reviewed. However, these databases provide huge data from primary studies on health and nursing.

\section{Conclusion}

Studies on culturally adapted psychoeducation were still limited. Although most of studies were RCT done in the outpatient department of hospital of developing countries in Asia, few of studies did follow up. Therefore, long-term effect could not be found. Studies were mostly developed from multifamily family group psychoeducation adapted to culture from some culture theories by modifying language and content through cultural specific norm and belief. Intervention was offered with various content, session, duration, and media. Most of intervention was delivered by face to face. Most of output for family caregiver was burden followed by coping and stigma. 
Future studies need to conduct in other ethnics. Furthermore, the culturally adapted psychoeducation should be more effective, simple, practical, and easy to conduct. Therefore, it is necessary to test the effectiveness of the intervention related to content, media, ways to deliver, and long-term effect.

\section{Acknowledgment}

This research was funded by Universitas Padjadjaran with contract number 2393/UNG.L/LT/2019. The author would like to thank Universitas Padjadjaran and supervisors who have provided suggestions and support. In addition, we would like to thank Hartiah Harun, Ph.D, who has helped in conducting this review.

\section{References}

1. Herzog EA, Varcarolis EM. "Schizophrenia" In: Varcarolis ME., Halter JM, editors. Foundation of Psychiatric Mental Health Nursing: A Clinical Approcah. $6^{\text {th }}$ ed. St Louis, Missouri: Saunders; 2010. p. 306-43.

2. Ritchie H, Roser M. Mental Health. Our World Data; 2018. Available from: https://www.ourworldindata.org/mentalhealth\#licence. [Last accessed on 2021 Jun 14].

3. Świtaj P, Anczewska M, Chrostek A, Sabariego C, Cieza A, Bickenbach J, et al. Disability and schizophrenia: A systematic review of experienced psychosocial difficulties. BMC Psychiatry. 2012;12:1-12. https://doi.org/10.1186/1471-244x-12-193 PMid:23137171

4. James SL, et al. Global, regional, and national incidence, prevalence, and years lived with disability for 354 Diseases and Injuries for 195 countries and territories, 1990-2017: A systematic analysis for the Global Burden of Disease Study 2017. Lancet. 2018;392(10159):1789-58. https://doi.org/10.341 O/f.731220250.793569875

PMid:30496104

5. World Health Organization. Mental Health Policies and Action Plans. Geneva: World Health Organization; 2007. Available from: https:// www.who.int/mental_health/policy/services/1_MHPolicyPlan Infosheet.pdf?ua=1. [Last accessed on 2021 Jun 15].

6. Thornicroft G, Deb T, Henderson C. Community mental health care worldwide: Current status and further developments. World Psychiatry. 2016;15(3):276-86. https://doi.org/10.1002/ wps. 20349

\section{PMid:27717265}

7. Irazabal M, Pastor C, Molina MC. Family impact of care and respite service: life experiences of mothers of adult children with intellectual disability and mental disorders. Rev Cercetare Interv Soc. 2016;55:7-18.

8. Friedman MR, Bowden V, Jones E, editor. Introduction to the family. In: Family Nursing: Research, Theory, and Practice. $5^{\text {th }}$ ed. New Jersey: Pearson Education, Inc.; 2003. p. 1-34.

9. Jenkins L, Ruth R. Caring for families in the home. In: Home Care Nursing Practice: Concepts and Application. $4^{\text {th }}$ ed. St Louis, Missouri: Mosby, Elsevier; 2006. p. 38-70.
10. Suryani S. A critical review of symptom management of auditory hallucinations in patient with schizophrenia. J Keperawatan Padjadjaran. 2015;3(3):150-7.

11. Young L, Murata L, McPherson C, Jacob JD, Vandyk AD. Exploring the experiences of parent caregivers of adult children with schizophrenia: A systematic review. Arch Psychiatr Nurs. 2019;33(1):93-103. https://doi.org/10.1016/j.apnu.2018.08.005 PMid:30663631

12. Fekadu W, Mihiretu A, Craig TK, Fekadu A. Multidimensional impact of severe mental illness on family members: Systematic review. BMJ Open. 2019;9(12):1-12. https://doi.org/10.1136/ bmjopen-2019-032391

13. Suryani $\mathrm{S}$. Caring for a family member with schizophrenia: The experience of family carers in Indonesia. Malaysia J Psychiatry. 2015;24(1):15.

14. Rafiyah I. Sundanese caregivers burden caring for persons with schizophrenia. iCDMIC. 2017;1(1):1-7.

15. Sin J, Murrells T, Spain D, Norman I, Henderson C. Wellbeing mental health knowledge and caregiving experiences of siblings of people with psychosis, compared to their peers and parents: An exploratory study. Soc Psychiatry Psychiatr Epidemiol. 2016;51(9):1247-55. https://doi.org/10.1007/ s00127-016-1222-7 PMid:27121259

16. Rafiyah I, Suttharangsee W, Sangchan H. Social support and coping of indonesian family caregivers caring for persons with schizophrenia. Nurse Media J Nurs. 2011;1(2):159-68.

17. Caqueo-Urízar A, Boyer L, Baumstarck K, Gilman SE. The relationships between patients' and caregivers' beliefs about the causes of schizophrenia and clinical outcomes in Latin American countries. Psychiatry Res. 2015;229(1-2):440-6. https://doi.org/10.1016/j.psychres.2015.06.033 PMid:26188641

18. Koschorke M, Padmavati R, Kumar S, Cohen A, Weiss HA Chatterjee $\mathrm{S}$, et al. Experiences of stigma and discrimination of people with schizophrenia in India. Soc Sci Med. 2014;123:149-59.

PMid:25462616

19. Hamaie $Y$, Ohmuro N, Katsura M, Obara C, Kikuchi T, Ito F, et al. Criticism and depression among the caregivers of at-risk mental state and first-episode psychosis patients. PLoS One. 2016;11(2):1-13. https://doi.org/10.1371/journal.pone.0156590 PMid:26918629

20. Bastug G, Karanci N. The impact of caregivers' expressed emotion and the patients' perception of expressed emotion on the positive and negative symptoms of patients with schizophrenia in a sample from Turkey. Dusunen Adam. 2015;28(2):127-39. https://doi.org/10.5350/dajpn2015280205

21. Pothimas N, Tungpunkom $P$, Chanprasit $C$, Kitsumban V. A Cross-sectional Study of Factors Predicting Relapse in People with Schizophrenia. Pac Rim Int J Nurs Res. 2020;24(4):448-59.

22. Nurmaela M, Suryani $S$, Rafiyah I. The relationship of family resilience with relapse in the schizophrenia patients at psychiatric unit. J Keperawatan Padjadjaran. 2018;6:340. https://doi.org/10.24198/jkp.v6i1.340

23. Opoku-Boateng YN, Kretchy IA, Aryeetey GC, Dwomoh D, Decker S, Agyemang SA, et al. Economic cost and quality of life of family caregivers of schizophrenic patients attending psychiatric hospitals in Ghana. BMC Health Serv Res. 2017;17(2):697. https://doi.org/10.1186/s12913-017-2642-0 PMid:29219074

24. Chen LF, Liu J, Zhang J, Lu XQ. Non-pharmacological interventions for caregivers of patients with schizophrenia: A meta-analysis. Psychiatry Res. 2015;235:123-7. https://doi. org/10.1016/j.psychres.2015.11.037 


\section{PMid:26639649}

25. Sin J, Gillard S, Spain D, Cornelius V, Chen T, Henderson C Effectiveness of psychoeducational interventions for family carers of people with psychosis: A systematic review and meta-analysis. Clin Psychol Rev. 2016;56:13-24. https://doi. org/10.1016/j.cpr.2017.05.002

26. McFarlane WR. Family Interventions for Schizophrenia and the psychoses: A review. Fam Process. 2016;55(3):460-82. https:// doi.org/10.1111/famp. 12235

PMid:28578249

27. Falloon I, Boyd J, Moss H, Cardin V, McGill C, Razani J. Behavioural family therapy for schizophrenia: A controlled twoyear study. Epidemiol Community Psychiatry. 1985;146:481-5. https://doi.org/10.1007/978-1-4684-4700-2_73

28. Anderson C, Hogarty G, Reiss D. The psychoeducational family treatment of schizophrenia. New Dir Ment Health Serv. 1981;62:79-94. https://doi.org/10.1002/yd.23319811207

29. Bradley GM, Couchman GM, Perlesz A, Nguyen AT, Singh B, Riess C. Multiple-family group treatment for english-and vietnamese-speaking families living with schizophrenia. Psychiatr Serv. 2006;57(4):521-30. https://doi.org/10.1176/ ps.2006.57.4.521 PMid:16603748

30. Spencer H. What is Culture ? Compiled. New York: Global Core Concepts; 2012.

31. Pooe JM, Sokudela B, Roos JL, Motlana LM, Dlamini N, Snyman M. Testing the effectiveness of existing psycho-educational material (The Alliance Programme) for patients suffering from schizophrenia in the South African context. African J Psychiatry. 2010;13(4):302-8. http://doi.org/10.4314/ajpsy.v13i4.61881

32. Bernal G, Jiménez-Chafey MI, Domenech Rodríguez MM. Cultural adaptation of treatments: A resource for considering culture in evidence-based practice. Prof Psychol Res Pract. 2009;40(4):361-8. https://doi.org/10.1037/a0016401.

33. Shin SK. Effects of culturally relevant psychoeducation for Korean American families of persons with chronic mental illness. Res Soc Work Pract. 2004;14(4):231-9. https://doi. org/10.1177/1049731503262130

34. Ferrin M, Moreno-Granados JM, Salcedo-Marin MD, Ruiz-Veguilla M, Perez-Ayala V, Taylor E. Evaluation of a psychoeducation programme for parents of children and adolescents with ADHD: Immediate and long-term effects using a blind randomized controlled trial. Eur Child Adolesc Psychiatry. 2014;23(8):637-47. https://doi.org/10.1007/s00787-013-0494-7 PMid:24292412
35. Arksey H, O'Malley L. Scoping studies: Towards a methodological framework. Int J Soc Res Methodol Theory Pract. 2005;8(1):19-32.

36. Kung WW, Tseng YF, Wang Y, Hsu PC, Chen D. Pilot study of ethnically sensitive family psychoeducation for chineseamerican patients with schizophrenia. Soc Work Ment Health. 2012;10(5):384-408. https://doi.org/10.1080/15332985.2012.67 8570

37. Shiraishi N, Watanabe N, Katsuki F, Sakaguchi H, Akechi T. Effectiveness of the Japanese standard family psychoeducation on the mental health of caregivers of young adults with schizophrenia : A randomised controlled trial. 2019;1-12. https:// doi.org/10.1186/s12888-019-2252-y

38. Barrio C, Yamada AM. Culturally based intervention development: The case of Latino families dealing with schizophrenia. Res Soc Work Pract. 2010;20(5):483-92. https:// doi.org/10.1177/1049731510361613.

39. Kopelowicz A, Zarate R, Wallace CJ, Liberman RP, Lopez SR, Mintz J. The ability of multifamily groups to improve treatment adherence in Mexican Americans with schizophrenia. Arch Gen Psychiatry. 2012;69(3):265-73. https://doi.org/10.1001/ archgenpsychiatry.2011.135 PMid:2393219

40. Khalil AH, ELNahas G, Ramy H, Abdel Aziz K, Elkholy $H$, El-Ghamry R. Impact of a culturally adapted behavioural family psychoeducational programme in patients with schizophrenia in Egypt. Int J Psychiatry Clin Pract. 2019;23(1):62-71. https://doi. org/10.1080/13651501.2018.1480786 PMid:30015534

41. Husain MO, Khoso AB, Renwick L, Kiran T, Saeed S, Lane S, et al. Culturally adapted family intervention for schizophrenia in Pakistan: A feasibility study. Int J Psychiatry Clin Pract. 2020;25(3):258-67. https://doi.org/10.1007/s10597-010-9305-5 PMid:32930011

42. Chow W, Law S, Andermann L, Yang J, Leszcz M, Wong J, et al. Multi-family psycho-education group for assertive community treatment clients and families of culturally diverse background: A pilot study. Community Ment Health J. 2010;46(4):364-71.

\section{PMid:20414724}

43. Katsuki F, Takeuchi H, Inagaki T, Maeda T, Kubota Y, Shiraishi N et al. Brief multifamily Psychoeducation for family members of patients with chronic major depression: A randomized controlled trial. BMC Psychiatry. 2018;18(1):1-14. https://doi.org/10.1186/ s12888-018-1788-6

PMid:29929495 